\title{
Marketing Research of the Russian State Historical Museum Lecture-Hall Visitors
}

\author{
Roman Sidorchuk $^{1} \&$ Olga Grineva ${ }^{1}$ \\ ${ }^{1}$ Department of Marketing, Plekhanov Russian University of Economics, Moscow, Russian Federation \\ Correspondence: Roman Sidorchuk, Department of Marketing, Plekhanov Russian University of Economics, \\ Moscow, 127055, Russia. Tel: 7-926-218-1916. E-mail: Sidorchuk.RR@rea.ru
}

Received: October 28, 2014

Accepted: October 30, $2014 \quad$ Online Published: January 15, 2015

doi:10.5539/mas.v9n3p226

URL: http://dx.doi.org/10.5539/mas.v9n3p226

\begin{abstract}
The present paper demonstrates study results concerning visitors of the Russian State Historical Museum lecture-hall. Lecture-hall is a special space in the museum. To develop a marketing program for a lecture-hall, it is necessary to investigate its visitors. This study aimed at exploring the social and demographic characteristics of lecture-hall visitors; motivation for a lecture-hall visiting; duration of a series of lectures, and sources of information about the lectures. The study used a questionnaire survey of the museum lecture-hall visitors. These results demonstrate that the main visitors are middle-aged and elderly people, and lecture subject matters are the most important criterion when choosing a lecture. Popular are the lectures on the history of Russia and other countries. Short courses of lectures are most convenient for visitors. The main sources of information about the lectures are ads at the museum and online notifications. On the basis of the results obtained there were proposed recommendations for the development of communication and pricing policies of the lecture-hall.
\end{abstract}

Keywords: lecture-hall, museum marketing, lecture-hall marketing, marketing strategy, marketing research, public space, customer loyalty, communication strategy, visitors' satisfaction

\section{Introduction}

The traditional role of the museum is to inform the public about the culture and history. At the same time, the development of interactive media entertainment and electronic media demanded from museums to review their role in the society. As noted by Anderson (2004), with the 1990s, museums began to recognize their role as part of the entertainment industry, and change their practices and policies to become more focused on their audience. On the other hand, museums are in no hurry to consider marketing activities in their field work. For example, in the UK museum sector, the term "marketing" was not used until the late 1980-ies (Kawashima, 1997). Museum administrations possess some skepticism about the usefulness of marketing (Kolb, 2000). Simultaneously with skepticism, the museum administration is called upon turning to marketing tools for visitors' attraction. As it was noted by Rentschler (2002), for the past 25 years, museums responded to the interests of their visitors by incorporating marketing into their organizational strategy. This requires museums to act as a business organization. (McLean, 1997; Kotler \& Kotler, 1998). One of the most important marketing tools of the museums is the study of the target audiences. Investigation of the target audience of the museum allows developing approaches to the marketing program formation and providing museum with a more attractive look (Mokhtar F. M. \& Kasim A., 2011).

\section{Review of the Literature}

Interest in marketing within the Russian museums started showing itself only for the last few years. One of the marketing problems of Russian museums is associated with certain difficulties in the formation of marketing strategies on the by-products. One of such products in museum is a lecture-hall. In recent years, the population of Russian cities demonstrates a tendency towards rebirth of interest in visiting various lecture-halls (Kurmeeva, 2013). Such interest is expressed both in musical and literary or educational lectures (Lanik \& Bajanova, 2014). Attendance of lectures begins to compete with other forms of entertainment. At the same time, not all museum visitors show their interest in lecturer-halls. For example, the lecture-hall of the State Historical Museum (SHM) located on the Red Square in Moscow, challenges the problems concerning the number of its visitors. At the time of the study, the lecture-hall ticket price was included into the entrance fee to the museum. Management of the State Historical Museum in search of additional funding proposes to visit its lecture-hall as a separate paid 
service. The challenge of developing a marketing program for the modernized services is enhanced in the absence of regular museum marketing. The present study establishes two unique goals for the SHM lecture-hall: (1) to raise funds from the sale of tickets to a lecture-hall, and (2) organize educational activities in lecture-hall for the target groups of visitors. To achieve these goals the SHM lecture-hall needs to have a marketing program developed, which would be based on a study of lecture-hall visitors. Consideration must be given to that the young audience (within the broad context from 17 to 28 years old) is probably one of the most difficult segments(Sidorchuk \& Grineva, 2013) to be attracted to the museum lecture-hall. As it is emphasized by Willis, and et al., (1990), youth culture is a way of life, which is tuned to opposing institutional or "adult" culture. This probably explains why the literature review on youth and art museums suggests that they consistently make up a small percentage of visitors (Xanthoudaki, 1998; Australian Museums Online, 2005). A typical portrait of a group of people who frequent the museum, according to (Bennett \& et al., 1999), are "highly educated adults with high income and social status". Thus: Hypothesis 1: On the whole, lecture-hall visitors belong to the older age groups. Given the fact that at the time of the study, a museum admission ticket was simultaneously a ticket to the museum lecture-hall, we can assume: Hypothesis 2: In 70\% of cases, a visit to a lecture-hall is not the purpose of the visit itself. Based on the fact that many of the lectures in the lecture-hall consist of cycles that can last for several months, we can assume: Hypothesis 3: Short courses of lectures are perceived by visitors better. The existing system of informing lecture-hall consumers is not effective enough, and taking into account the views of the lecture-hall staff, it can be assumed: Hypothesis 4: The periodic printed products are the main sours of information about lectures.

\section{Methodology}

In order to investigate the set of hypotheses, the study used quantitative and qualitative approaches. Since a similar study is conducted in the State Historical Museum for the first time, researchers have found it necessary to first conduct qualitative research in the form of semi-structured interviews with two visitors and the expert. A study of such kind made it possible to obtain preliminary information and assessment of lecture-hall services by comparing the views of lecture-hall visitors and museum expert. Selection of visitors for the qualitative study carried a random nature. The visitors chosen were people regularly attending the lecture-hall and those who came to the lecture-hall for the first time. As an expert, there was chosen a representative of the consulting company working in the field of museum consulting. Quantitative phase of the study was conducted using a questionnaire. While forming the study sample, there were taken into account the following aspects: capacity of the lecture-hall - 120 visitors, average attendance of the lecture-hall - 15-25 visitors per lecture. The sample size must correspond to the result with $\pm 10 \%$ accuracy at confidence level of $95.4 \%$. Thus, the required sample size is 84 respondents. The researchers did not target gender or age representativeness, sampling method was a non-statistical method of "convenience", as it was the only available within existing constraints. The survey lasted for 3 weeks, in the lecture-hall, after the lectures. The questionnaire consisted of 27 questions, 26 of which were closed, using the Likert scale.

It should be noted the limitations of our study. Firstly, the lack of random sampling method limited the significance of the results due to the inability of extrapolation of these data to the entire population. Secondly, there was no possibility of stimulating lecture-hall visitors completing the questionnaire by prizes or gifts, which effectively limited the number of people willing to take part in the survey. Thirdly, the time constraints associated with the irregularity of the lectures, influenced the sample formation.

Requisite part of the questionnaire included a list of the main socio-demographic characteristics of visitors and contained 8 questions.

Filtering was the question: "Do you live in Moscow / Moscow area or came here for visit?" For the purposes of this study, it was important to interview the audience that had the opportunity to attend the State Historical Museum lectures on a regular basis,

A series of questions was aimed at defining the current model of behavior of lecture-hall visitors. For example, the question "Which places do you visit for leisure?" revealed the most obvious competitors, as well as identified the new ones, not recorded. The question "Where do you get information about cultural events?" provided an opportunity to identify the most effective media channels to develop a communication strategy for the lecture-hall. The question "How often do you attend lectures / workshops?" was aimed at defining the current visitors able to be offered additional types of lectures and other educational products in the museum.

Also in this part of the questionnaire we identified the factors, which could affect the selection of lecturers and their importance to the respondents, the sources of information about the lecture. The need to develop self-communication strategy for the lecture-hall is a relevant ongoing challenge of the museum management. 
It was important to find out the degree of planning a visit to the lecture-hall as an independent campaign, regardless of the visit to the museum ("Is your visit to the lecture-hall the main purpose of your museum visit?"). At the time the study took place, all the visitors were admitted to the lecture-hall by a museum ticket, and this made it impossible to determine, which part of the total number of the museum visitors came only and purposefully to the lecture-hall itself. Improving the efficiency of each of the museum structural units and the museum just in general is one of the most important goals established at the Ministry of Culture of Russia (Medinsky, 2013). This issue was important as an attempt to determine degree of how the museum and lecture-hall audiences can be considered as disjoint ones.

The next set of questions was aimed at clarifying the visitor satisfaction with the services provided.

The question "Which lecture topics are of the most interest to you?" was necessary for comparing the current thematic plan of the lecture-hall and wishes of its visitors. The question "Do you visit the full series of lectures?" was intended to determine the feasibility of complete cycles of lectures and visitors interested in them. The next question "Which series of lectures is the most convenient for you?" served for understanding the duration of the most popular series of lectures. As well as the question: "Is the time of the lecture convenient to you?", that allowed to get closer to an understanding of the format and schedule of lectures, suitable for the current visitors.

Assessment of motives for lectures attendance ("Why did you come to the lecture?") helped to define more clearly the portrait of the current lecture-hall visitor, and the ultimate goal was to build a product that meets the requirements of the visitors.

The most important for the purposes of the study was a set of questions designed to determine visitors' readiness to purchase tickets to the lecture-hall. One of the strategic objectives of the lecture-hall is the task of entering the recoupment level and formation of additional revenues, but in the absence of a clear understanding of how the introduction of a separate ticket system can attract or repel visitors, the lecture-hall management is not ready to risk the current audience of loyal visitors. Availability of services for vulnerable people - the benefits for pensioners, students and the high level of service quality (lectures are given by the professors of the Moscow universities, leading researchers of the museum) and convenient location (city center, the intersection of the three subway lines) make the lecture-hall a very important player in the market of educational leisure. Many people attend the lecture-hall for years, and it is important to preserve and maintain the social function of lecture-hall as a place to provide educational entertainment for different population segments. Analysis of the responses to the statement options: "I will attend lectures for an individual fee," "Introduction of a separate ticket to the lecture-hall will not affect my attendance at lectures", "Introduction of a separate ticket to the lectures is totally unacceptable" allowed to find out the percentage of visitors who were willing to consider the introduction of individual tickets to the lecture-hall.

\section{Obtained Results}

The results of the survey demonstrates that $76 \%$ of visitors are women and only $24 \%$ of them are men. The age of respondents ranges from 17 to 86 years with an average of 43 years.

Figure 1 presents data on the employment of visitors. Among respondents dominate people who are currently employed- $42 \%$, as well as a large share of pensioners and students occupy $36 \%$ and $18 \%$, respectively. The overwhelming majority of respondents have a university degree (68\%). Respondents currently being university students possess $18 \%$, and people with secondary or incomplete higher education $-14 \%$.

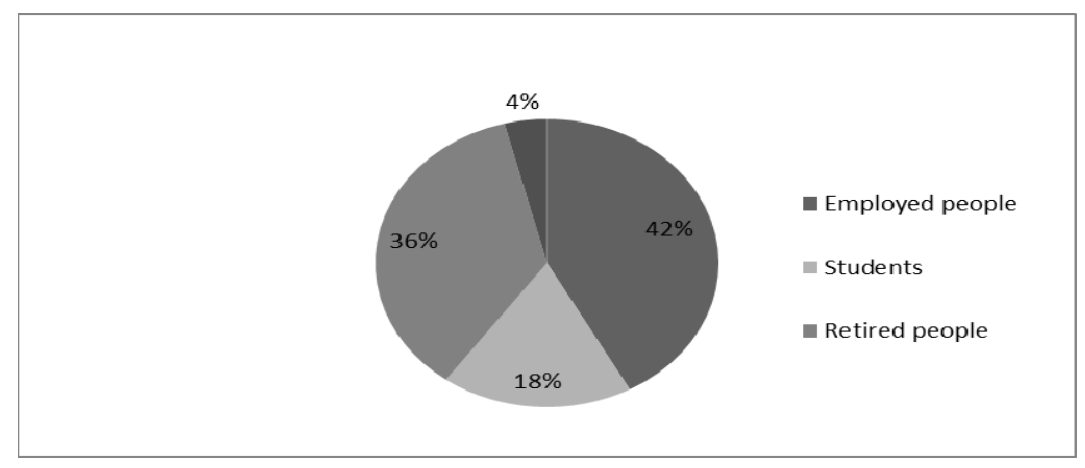

Figure 1. Respondents structure by area of their activity 
The findings lead to the conclusion that the respondents are mostly educated people, or are in the process of obtaining a higher education. Level of education allows them to comfortably take the format of presenting information - serious, with a special terminology, an abundance of factual material, without any attempt to ideological pressure. Judging from this information, it can also be concluded that the conglomerations of future lecture-hall audiences may be universities, high schools, and "intellectual-intensive" industries (consulting, media industry, high technology). For this audience it is very important to be able to form their own opinions on a wide range of issues, and the lecture-hall can provide them with such an opportunity.

Understanding of the problem of the lecture-hall visitors' income was one of the key moments of the study, since it directly affected the ability and willingness of people to buy a lecture-hall ticket. Among the respondents, the average income level belonged to $44 \%$ of audience. People with low and slightly below the average level income possessed $34 \%$ of those surveyed. The share of wealthy people with high and slightly above average level income was $20 \%$.

The most common place of leisure for the respondents was other lecturer-halls $-53 \%$ among leisure activities reported by respondents. In this case, the most popular among respondents was the Tretyakov Gallery lecture-hall. Other popular places for leisure activities also included libraries $(40 \%)$ and art spaces $(10 \%)$. The possibility of partnership agreements and cross-information on the activities of other educational leisure places may be the next lecture-hall's step on its way of attracting and stimulating attendance of loyal audiences.

These results demonstrate that the typical SHM lecture-hall visitors are people working or staying retired, permanently residing in Moscow or the Moscow region, with an average level of income, actively attending cultural events (other lecture-halls, art spaces, libraries).

The average age of respondents was 43 years. This confirms the hypothesis 1 that the main visitors of the SHM lecture-hall are people from older age category.

As part of the behavior model preparation, we studied the visitors' source of information about the lecture-hall and various information and cognitive activities of the lectures. Questioning revealed that the most popular media channels for information were primarily the Internet, television, to a lesser extent social networks and printed materials, as shown in Figure 2.

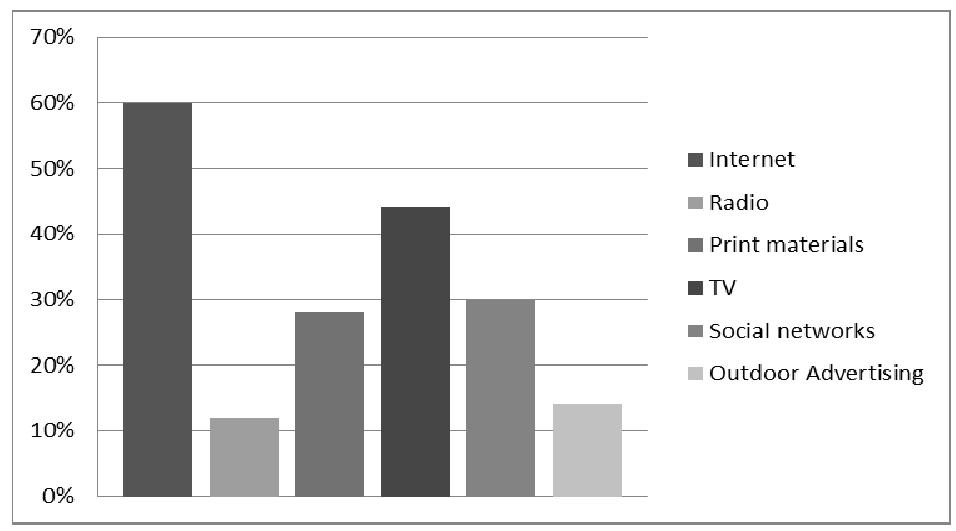

Figure 2. Ways of obtaining information on cultural events

In addition, a majority of the respondents received information on the lecture-hall in the museum (42\%) and from the Internet $(30 \%)$. None of the respondents indicated publications as a source of information. Thus, the results refute the hypothesis 4 that the main source of information on the lecture-hall is the publications and periodicals. These data suggest that most of the lecture-hall visitors obtain news in the museum.

Attendance statistics demonstrates that the number of people visiting various museums 1-2 times a week and 1-2 times a month is almost similar, $33 \%$ and $35 \%$, respectively. Thus, the largest number of respondents is the people who are ready to spend their free time exactly in the museum; they are culturally-oriented and constantly strive to expand their horizons.

Statistics on visiting the SHM lecture-hall showed that only $33 \%$ of respondents visit the museum 1-2 times a week. This is the percentage of our regular, loyal visitors. $44 \%$ of respondents visit the museum at least once a year. As shown by the data on visits to various museums, the majority of respondents often go to museums, but judging from the above statistics, specifically GIM is rarely attended. Currently available range of cultural 
leisure activities in Moscow is wide enough, the struggle for free time consumers increases. Taking into account these data, the lecturer-hall should increase activity in the field of information and awareness of potential audiences.

Quantitative studies demonstrated that the topics of lectures were an essential criterion for lecture hall selection (Figure 3). Respondents said that in most cases the subject of the lecture was "highly important" when deciding about visiting lecturers. The schedule of the lectures and the name of the lecturer were also important for visitors The ticket price and the subscription availability appeared to be almost irrelevant for the respondents. This suggests that at a convenient schedule and well-proven and well-known lecturer, the ticket price may be higher, and it will not affect the lecture-hall attendance.

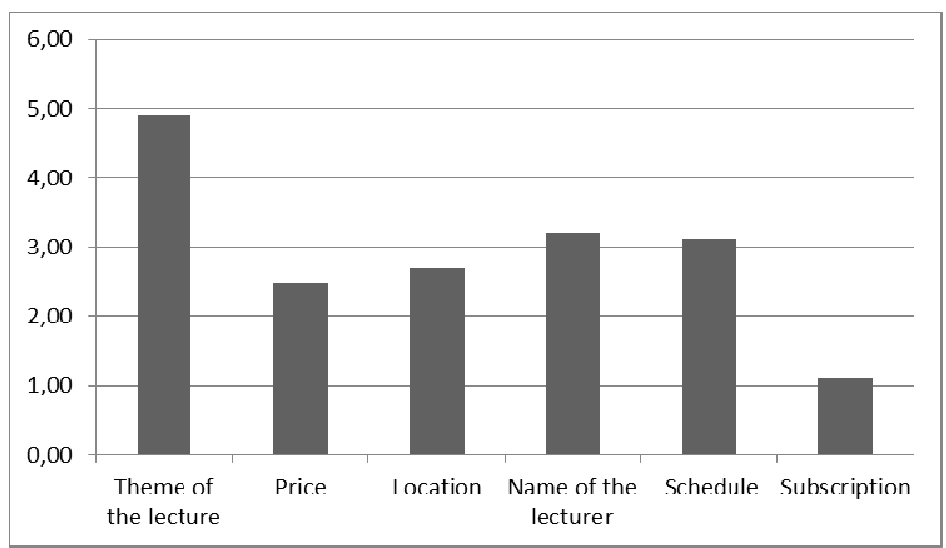

Figure 3. The main criteria for lecture-hall selection

Preferences of the respondents on the subject matter of the lectures were as follows: the most popular was the topic of ancient history (the factor 4.02 out of 5), and the History of Russia (4 out of 5 possible). More wide dissemination of information on the planned series of lectures concerning these areas of knowledge may increase the amount of visitors. The time of lecture performance is acceptable for the majority of respondents.

In answering the question about the preferred time length of the lecture, $61 \%$ of respondents mentioned the cycle in 1-3 weeks as the most convenient one. This confirms the hypothesis 3 , that short courses of lectures are better perceived by lecture-hall visitors.

A series of questions about the possibility of introducing individual lecture-hall tickets revealed that:

- $65 \%$ of respondents buy a ticket and purposefully attend the lecture-hall

- $66 \%$ of respondents are willing to attend lectures for a fee

- $69 \%$ of respondents said that the introduction of an individual lecture-hall ticket would not affect their attendance.

The obtained results refute the hypothesis 2 that for the $70 \%$ of visitors, lecture-hall attendance is not the purpose of the visit. Overall, respondents are loyal to the introduction of the individual lecture-hall tickets, because most of them attend it purposefully.

\section{Conclusions}

The data obtained allow recommending a number of operational measures to improve the lecture-hall attendance.

Quantitative studies demonstrated that the main source of information for the respondents was the television, internet and periodicals. The high cost of promotion on TV and radio stations is necessary to be focused on other communication channels. Informational source should be mainly focused on informing SHM lecture-hall audiences in the museum and on the Internet. Qualitative studies indicated that a warning system on the internet was very inconvenient. Improving the site navigation, allocating a separate page for the lecture-hall with active communication on it, creating a convenient system of search schedules and topics of lectures can significantly increase the visitors' satisfaction with the process of information provision. It is also necessary to pay attention to the three other communication capabilities of the Internet, mainly to the social networks. It is advisable to create and actively support the communities in social networks such as VK, Odnoklassniki, Facebook and Twitter. Printed products also remain an important channel of communication. There should be created brochures 
and other printed forms informing the target audience. Information should be complete: the ticket price, lecture series, address, dates, etc.

The most important criterion for the lecture-hall selection within the analysis of qualitative and quantitative studies appeared to be the theme of lectures. The most popular topics were the Russian History and History of Foreign Countries. The main lectures in the State Historical Museum are already devoted to these topics, but to attract more attention, it makes sense to deepen the integration of those lectures on current events of life. First of all, it makes sense to correlate the lecture themes with cultural events in Russia and in the world. The series of lectures should be reduced if possible, as almost half of the respondents seem to mainly prefer brief lectures.

Statistical analysis showed that more than half of the visitors would continue to attend lectures after the introduction of a separate ticket and they did not consider this to be unacceptable. A separate ticket can be put into perspective, when the number of loyal visitors increases during the implementation of recommendations. In general, visitors are willing to pay for the ticket itself, but without a sufficient number of interested people, the service of the lecture-hall, even for a museum fee will be unprofitable. As in the case of a subscription, it is required to work out the design of the ticket, so that it would arouse a desire to keep it as a souvenir.

Taking into account the results obtained, it is necessary to provide for the establishment of the strategic marketing plan for lecture-hall. A key starting point is the extension of the target audience.

Currently, the average age of a lecture-hall visitor is 43 years, which suggests that much of the audience from 18 to 30 years is slightly covered. At the same time, the decrease in the average age of visitors may lead to the fact that these visitors will be with the lecture-hall at the next stages of their development, after being married, while organizing children's leisure, at the stage of family development with older children growing up. That is why the work with attracting more young audience into the lecture-hall is strategically important and it should be supported by the specially developed new products and communication policy.

Analysis of visitors of socio-cultural institutions, which include lecture-halls, can greatly help their management in the development of sound marketing strategy and tactical tasks, decision-making to be based on an understanding of their audience. Each object has a unique audience, not an exception is the SHM, with its long history of public lectures, the first of which was delivered in 1889 .

In the course of the study of the State Historical Museum lecture-hall, there were completed the targets set in the TOR: there was identified and described the main target audience of the lecture-hall, analyzed the degree of satisfaction with the services of the museum, as well as identified the key competitors.

Keen public interest in the cultural heritage objects and enhancement of their effectiveness makes actual the regular visitor studies executed by these institutions. The results of such research can and should be used in determining the strategy and tactics of the lecture-halls, museums and other educational leisure establishments.

\section{References}

Anderson, G. (ed.). (2004). Reinventing the museum: Historical and contemporary perspectives on the paradigm shift. Walnut Creek CA: Altamira.

Bennett, T., Emmison, M., \& Frow, J. (1999). Accounting for tastes: Australian everyday cultures. Melbourne: Cambridge University Press.

Kawashima, N. (1997). Museum management in a time of change: Impacts of cultural policy on museums in Britain, 1979-1997. Working Paper 3. Centre for the Study of Cultural Policy, University of Warwick: November.

Kolb, B. M. (2000). Marketing cultural organisations: New strategies for attracting audiences to classical music, dance, museums, theatre and opera. Oak Tree Press: Dublin.

Kotler, N., \& Kotler, P. (1998). Museum Strategy and Marketing. San Francisco: Jossey-Bass.

Kurmeeva, N. K. (2013) Extracurricular forms of musical and aesthetic education: to the history of the question. VESTNIK OSU, 7(156), 153-160.

Lanik, T. V., \& Bajanova, E. A. (2014). Immersion in the classics from the experience of literary and educational lectures. Library business, 212(2), 7-10.

McLean, F. (1997). Marketing the Museum. London: Routledge. http://dx.doi.org/10.4324/9780203277744

Medinsky, V. (2013). Interview for Literary Gazett. Retrieved September 9, 2013, from http://medinskiy-vr.livejournal.com/69639.html 
Mokhtar, F. M., \& Kasim, A. (2011). Motivations for visiting and not visiting museums among young adults: a case study on UUM students, International conference on management (ICM 2011) proceeding, Hydro Hotel, Penang, Malaysia13th - 14th June 2011, ISBN PROCEEDING: 978- 967-5705-03-8, pp.1398-1457.

Rentschler, R. (2002). Museums and performing arts marketing: The age of discovery. Journal of Arts Management, Law, and Society, 32(1), 7-14. http://dx.doi.org/10.1080/10632920209597330

Sidorchuk, R. R., \& Grineva, O. O. (2013). Communication Strategy Verkhoturye as a tourist center of the Urals, V-th International scientific-practical conference: Modern Economy: Concept and model of innovative development. Moscow, Russia: Plekhanov Russian University of Economics.

Willis, P., Jones, S., Joyce, C., \& Hurd, G. (1990). Common culture: Symbolic work at play in the everyday cultures of the young. Milton Keynes: Open University Press.

Xanthoudaki, M. (1998). Educational provision for young adults as independent visitors to art museums and galleries: Issues of learning and training. Museum Management and Curatorship, 17(2), 159-172. http://dx.doi.org/10.1080/09647779800401702

\section{Copyrights}

Copyright for this article is retained by the author(s), with first publication rights granted to the journal.

This is an open-access article distributed under the terms and conditions of the Creative Commons Attribution license (http://creativecommons.org/licenses/by/3.0/). 